\title{
COUPLing NoRMAL AND SHEARING STRESSES TO USE in Finite ELEment ANalysis of SoIL COMPaCtion
}

\author{
R. L. Raper, C. E. Johnson, A. C. Bailey
}

\begin{abstract}
A finite element model was modified to use a constitutive relationship of soil compaction that included the effects of both normal and shearing stresses. Predicted values of soil stress were compared against results from a laboratory experiment. All predicted values at final deformed depths less than $0.3 \mathrm{~m}$ were within the $95 \%$ confidence intervals of the measured values. but at deeper depths most of the predictions fell outside the $95 \%$ confidence intervals of the measured values. Keywords. Finite element analysis. Model, Soil compaction.
\end{abstract}

$\mathrm{S}$ oil compaction models are useful tools for estimating the magnitude of soil compaction. Typically, the input for these models is the magnitude of stress at a point in the soil profile, and output is the amount of volumetric strain for a prediction of soil density. The input requirements present a problem because values of stress in the soil are not normally known. Usually, the only inputs fanners know are the weight of their vehicle, tire size and inflation pressure or track size, and their particular soil condition. Farmers want to know (a) the maximum amount of soil compaction that will take place in the soil, (b) the extent of damage to the soil (i.e., how deeply it will be compacted excessively), (c) how much sinkage the load causes, and (d) how their crop yield will be affected. One must conclude that current soil compaction models are inadequate.

Finding a method to take the given inputs and produce some or all of the wanted outputs has been a subject of research for half a century. Finite element analysis comes closest as the most logical candidate. This method can be used to predict all the unknowns except item d. No other method that has been proposed can predict stress propagation, magnitude of soil compaction, and surface deformation. If an accurate constitutive relationship is known for the soil condition, the only obstacle is adequate computational facilities. With the proliferation of powerful microcomputers, this is becoming irrelevant.

Researchers have investigated using the finite element method for soil compaction prediction since 1969 (Perumpral, 1969). As computers have become more powerful, the finite element models have also become more powerful and complicated. Unfortunately, the

Article has been mimed and approved for publication by the Power and Machinery Div. of ASAE. Presented as ASAE Paper No. 90-,086.

Contribution of USDA-ARS and Auburn University. Alabama Experiment Station Journal No. 2-902613P.

The authors are Randy L Raper, ASAE Member Engineer, Agricultural Engineer. National Soil Dynamics Laboratory (NSDL), USDA-Agricultural Research Service, Auburn, Ala., Clarence E. Johnson, ASAE Member Engineer, Professor, Agricultural Engineering Dept., Alabama Agricultural Experiment Station, Auburn University, Ala., and Alvin C. Bailey, ASAE Member Engineer, Agricultural Engineer, NSDL, USDA-Agricultural Research Service, Auburn, Ala. accuracy of the predictions is only as good as the constitutive relationships provided to the finite element model. Earlier attempts at using a finite element model to solve the soil compaction problem were probably hampered by deficiencies in constitutive stress-strain relationships for soil. Until recently, soil compaction models did not adequately relate shearing stress and strain. However, with the development of stress-strain-compaction relationships for soil at the National Soil Dynamics Laboratory (NSDL) and Auburn University, improvements in predicting soil compaction with the finite element method are possible.

The objectives of this research effort are to:

- Develop appropriate techniques for predicting tangential linear-elastic parameters from the constitutive relationship.

- Incorporate a soil compaction model that uses both normal and shearing stresses into a finite element model.

- Compare and evaluate the predicted stress levels against laboratory tests.

\section{LITERATURE R EVIEW}

The earliest soil compaction models considered the major principal compressive stress to be the most relevant predictor of soil compaction (Chancellor et al., 1958). Researchers assumed that for tire induced soil compaction, the stress that caused the most damage was the vertical stress. This theory was practical and was easily modeled in a shallow cylinder by performing a confined compression test (Larson et al., 1980). Because of the shallow soil depth, there was only slight stress variation from top to bottom, and the major principal stress was the controlling factor. This theory was reasonable for shallow cylinders, but is not adequate for deep field soils that have significantly larger shearing stresses.

As researchers learned more about the compaction process, other methods of predicting soil compaction were sought. Mean normal stress (one third of the first invariant of the stress tensor) was investigated by Vanden Berg et al. (1958). They observed that the mean normal stress was a better predictor of soil compaction than the major principal 
compressive stress which did not adequately consider the confining stress.

A continuation of this approach was used by Bailey et al. (1984). They established a relationship based on hydrostatically loaded soil samples in a triaxial apparatus. For the case of hydrostatic loading, the mea" normal stress equaled the hydrostatic pressure applied. Volumetric strain was predicted as a function of the applied stress.

$$
\varepsilon_{\mathrm{v}}=\left(\mathrm{A}+\mathrm{B} \sigma_{\mathrm{hyd}}\right) \times\left[1-\mathrm{e}^{\left(-\mathrm{C} \sigma_{\mathrm{hyd}}\right)}\right]
$$

$$
\begin{aligned}
& \text { where } \\
& \begin{array}{cl}
\varepsilon_{\mathrm{v}} & \text { volumetric strain, (change in volume/original } \\
& \text { volume) } \\
= & \text { hydrostatic stress }(\mathrm{kPa}) \\
\sigma_{\mathrm{hyd}} & \text { compactibility coefficients established by } \\
\mathrm{A}, \mathrm{B}, \mathrm{C}= & \text { fitting data to equation }
\end{array}
\end{aligned}
$$

This model tit the laboratory data well, but for field use it was limited by the assumption of hydrostatic stress loading.

Raper and Erbach (1990b) used equation 1 as a constitutive relationship in a nonlinear finite element model to determine if soil stresses could be accurately predicted. They modeled a flat circular plate and a spherical plate which applied a $12.5-\mathrm{kN}$ and a $25-\mathrm{kN}$ load to the soil surface. Results from the finite element model and from transducers placed in the soil showed that the prediction accuracy was affected by the load-applying devices. Stress values beneath the flat plate were predicted very accurately while those beneath the spherical disk were not. One of the reasons given for the inadequate predictions in the spherical disk loading case was that shear stress was not taken into consideration.

Other research indicated that the maximum amount of soil compaction did not occur near the surface where the load was applied (Chancellor et al., 1962). If the soil behaved like a solid continuum, the largest compaction should be next to the load application at the surface and should decrease as the distance into the soil increases. Soil behaves like a continuum only up to a point, however, and then behaves like a particulate medium as the shearing stresses become greater than the failure limits. When failure occurs, the soil moves and increased amounts of compaction are found some distance from the soil surface.

A" adequate soil mechanics description of the soil compaction process should include not only the normal stress effects but also shearing stress effects. Failure to include both sets of effects could limit the general effectiveness of the compaction model and make it unusable for field research. However, neither shearing stress nor its effects are easily measured in soil. The best method developed so far has been to use normal pressures measured in a particular orientation to calculate the shear stresses. A transducer that provides data from which the shearing stress can be calculated was developed at the NSDL and Auburn University by Nichols et al. (1987). This stress state transducer (SST) measured the normal stress in six directions, three of which arc orthogonal. All six measurements were used to establish the stress tensor from which the principal stresses were derived. From these stresses, the octahedral normal and shearing stresses were calculated.
The recognition of the importance of shearing stress led to the development of a new soil compaction model (Bailey and Johnson, 1989). This model predicts the volumetric strain as a function of the octahedral normal and shearing stresses.

$$
\bar{\varepsilon}_{\mathrm{v}}=\left(\mathrm{A}+\mathrm{B} \sigma_{\mathrm{oct}}\right) \times\left[1-\mathrm{e}^{\left(-\mathrm{C} \sigma_{o c t}\right)}\right]+\mathrm{D}\left(\frac{\tau_{\mathrm{oct}}}{\sigma_{o c t}}\right)
$$

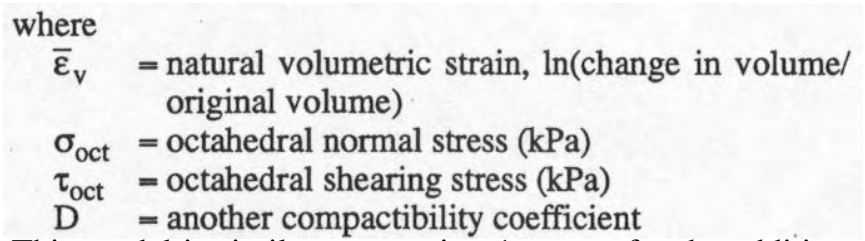

This model is similar to equation 1 except for the addition of the shearing stress component and the use of the natural strain definition. Limitations were placed on the shearing stress component in the above model to indicate plastic flow. The restricting relationship is:

$$
\tau_{\text {octy }}=\mathrm{K} \sigma_{\mathrm{oct}}
$$

where $\tau_{\text {octy }}$ is the ultimate shearing stress at maximum density and $\mathrm{K}$ is the coefficient representing soil plastic flow yield. The value of $\mathrm{K}$ for a Norfolk sandy loam soil used in this experiment was 0.73 . If this restriction is not made, excessive values of volumetric strain are predicted at stress levels above plastic flow.

\section{MODEL DEVELOPMENT}

Two linear-elastic parameters are necessary for structural finite element models: Poisson's ratio and Young's modulus. Both parameters were initially defined for isotropic, homogeneous, linear-elastic materials. To use the linear-elastic parameters for a particulate material such as soil, certain of these assumptions must be neglected. Usually, the disregarded assumptions cause no problem and reasonable predictions result. However, it is important to note that the technology of finite element analysis was not developed for particulate material and problems CM occur because of the particulate nature of soil.

Poisson's ratio was originally defined as (Popov, 1976):

$$
v=-\frac{\text { lateral strain }}{\text { axial strain }}
$$

Values assumed for Poisson's ratio are between 0.1 (some concretes) and 0.5 (rubber). This relationship is assumed to hold for both tensile and compressive stresses. However, when using this relationship, we must remember that it was defined for a situation in which the normal stresses perpendicular to the axial direction was zero.

Applying the concept of Poisson's ratio to soil is valid, but certain assumptions must be made to obtain reasonable values from laboratory tests. The tensile stress that soil can withstand is very small and, therefore, tests to determine Poisson's ratio in soil arc usually compressive. Also, unless the soil is compacted or cemented, a small normal 
compressive stress in the lateral direction must be maintained to keep the soil from failing prematurely.

Soft soils should have a value of Poisson's ratio near 0 , while more structured, dense, clay soils may have values near 0.5. Low values of Poisson's ratio indicate that a force is not transferred very far laterally into soil and is absorbed near the point of application. High values of Poisson's ratio would mean that forces would be effectively transferred laterally and would influence more of the soil volume.

As a soil goes through the compacting process, Poisson's ratio will change. Initially, a soil may be very loose and have a low value of Poisson's ratio. As it is compacted, thereby increasing its Poisson's ratio, it will translate more force radially. Thus, Poisson's ratio should be considered variable throughout the soil compaction process. Assuming a high constant value initially would underpredict the soil compaction and its distribution.

A nonlinear relationship of Poisson's ratio is therefore needed to enable this parameter to vary with varying stress levels. A relationship that enabled Poisson's ratio to be incrementally calculated was developed by Duncan and Chang (1970).

$$
v=\frac{\Delta \varepsilon_{1}-\Delta \varepsilon_{\mathrm{v}}}{2 \Delta \varepsilon_{1}}
$$

where $\Delta \varepsilon$, is the incremental axial strain and $\Delta \varepsilon_{\mathrm{y}}$ is the incremental volumetric strain. This equation can be derived from the original definition (eq. 4) if axisymmetric geometry is assumed. I" their research, Duncan and Chang (1970) noted that this linear-elastic parameter was variable, but declared that portion of research to be beyond the scope of their article.

The Duncan and Chang (1970) relationship presented another problem because of its use of incremental axial and volumetric strain. The generally accepted method of calculating the linear-elastic parameters in a nonlinear manner is to take the finite element-calculated stresses and compute, from the constitutive relationship, a new value of Poisson's ratio and Young's modulus. But to use equation 5 to calculate Poisson's ratio, two values of axial and volumetric strain are needed. The method used to determine these two values was to compute one set of values at the finite element-calculated stress values and then to calculate another using stress values slightly lower than calculated. This second set of stresses came from decreasing the major principal stress by a minimal amount (we assumed 1/100th). A new set of axial and volumetric strains was then used to compute a value of Poisson's ratio.

Determining a value of axial strain from equation 2 also required the use of research conducted by Grisso et al. (1987) that suggested the following relationship.

$$
\frac{\bar{\gamma}_{\text {oct }}}{\bar{\varepsilon}_{\text {oct }}} \propto \frac{\tau_{\text {oct }}}{\sigma_{\text {oct }}}
$$

where $Y_{\text {oct }}$ is the natural octahedral shearing strain and $\varepsilon_{\text {oct }}$ is the natural octahedral normal strain. They investigated different loading paths below the plastic flow limit on several soils present in the soil bins at the NSDL and established proportionality constants for each.
Determining Poisson's ratio for this research effort involved using equations 3,5 , and 6 . First, the normal stresses $\sigma_{\mathrm{r}}, \sigma_{\theta}, \sigma_{\mathrm{z}}$, and the shearing stress $\tau_{\mathrm{rz}}$ for each element produced by the axisymmetric finite element model were used to calculate the principal stresses and the octahedral normal and shearing stresses. Next, the octahedral stress ratio was examined to decide if plastic flow had occurred (eq. 3). A problem with instability of the finite element model forced us to increase the values of the minor stress components up to a point that restricted plastic flow. The magnitude of the minor principal stress was derived from the axisymmetric relationships $\left(\sigma_{2}=\sigma_{3}\right)$ for octahedral normal and shearing stress and equation 3.

$$
\sigma_{3}=\left(\frac{\sqrt{2}-K}{\sqrt{2}+2 K}\right) \sigma_{1}
$$

where

$$
\begin{aligned}
& \sigma_{1}=\text { major principal stress } \\
& \sigma_{3}=\text { minor principal stress } \\
& \mathrm{K} \text {-coefficient representing soil plastic flow yield from } \\
& \text { equation } 3
\end{aligned}
$$

The portion of equation 7 contained in parentheses was calculated to be 0.24 for Norfolk sandy loam soil. This instability problem and modification procedure was due to uncompacted agricultural soils having little inherent strength. At low stress levels, a small amount of lateral stress was necessary to prevent uncompacted agricultural soil from collapsing. Knowing values of octahedral sheering stress, octahedral normal stress, and octahedral normal strain (volumetric strain), the octahedral shearing strain was calculated (eq. 6). Assuming axisymmetric geometry, the directional strains were then determined from their basic engineering relationships. These directional strains are then used to determine Poisson's ratio (eq. 5).

Figure 1 shows the effect of the presence of shearing stress on Poisson's ratio. When no shearing stress was present (hydrostatic loading), Poisson's ratio changed dramatically as the load increased across the mean normal stress range of 50 to $500 \mathrm{kPa}$. When the major principal stress was the only load applied and a maximum amount of shearing stress existed, the curve flattened dramatically. The interpretation of these curves is thus; in extremely loose soils where stresses are small (stress $<100 \mathrm{kPa}$ ), the presence of shearing stress tends to decrease Poisson's ratio, while in more compacted soils where the stresses are larger, the presence of shearing stress tends to increase Poisson's ratio.

The other linear-elastic parameter, Young's modulus, is somewhat easier to measure and predict. Young's modulus is a measure of the stiffness of the material and is defined as:

$$
E=\frac{\sigma}{\varepsilon}
$$

where

$$
\begin{aligned}
& \mathrm{E}=\text { Young's modulus }(\mathrm{kPa}) \\
& \sigma=\text { stress }(\mathrm{kPa}) \\
& \varepsilon=\text { strain }
\end{aligned}
$$




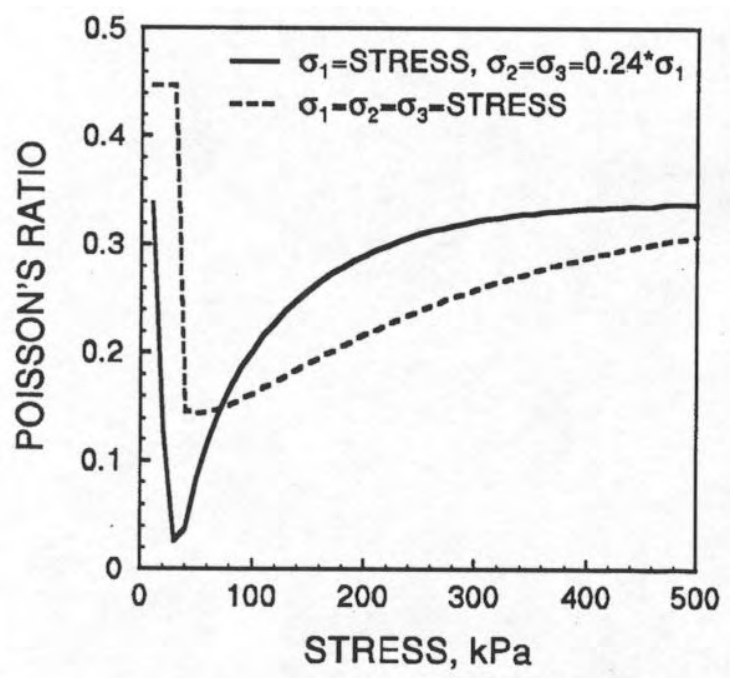

Figure 1-Poisson's ratio is predicted for a Norfolk sandy loam soil assuming either (a) the minor principal stresses, $\sigma_{2}$ and $\sigma_{3}$, are calculated from equation 7, or (b) all the principal stresses are equal.

Establishing a stress-strain curve for a "linear" material yields this linear-elastic parameter. Typical values for Young's modulus range from $2 \times 10^{6} \mathrm{kPa}$ for molded nylon to $200 \times 10^{6} \mathrm{kPa}$ for structural steel (Beer and Johnston, 1981).

For a material with a nonlinear relationship between stress and strain, a tangential Young's modulus was used that gave an instantaneous slope of the stress-strain curve. The method of predicting Young's modulus that made use of the shearing stress component involved using the volumetric strain predicted by the finite element model and solving equation 1 for an equivalent hydrostatic stress. Because the equivalent hydrostatic stress indicated equal pressures on all sides, the following relationship was used that related Young's modulus to Poisson's ratio and volumetric strain:

$$
\varepsilon_{v}=\frac{-3(1-2 v)}{E} \sigma_{\text {hyd }}
$$

Young's modulus can be determined by using the finite element-computed volumetric strain and the previously predicted Poisson's ratio. Figure 2 shows how this parameter responds to changes in principal stress and shearing stress. As with Poisson's ratio, this linear-elastic parameter also displays a great amount of sensitivity to changes in shearing stress.

The previously discussed methods of predicting Poisson's ratio and Young's modulus were used in an axisymmehic finite element model to predict the soil stresses and soil compaction beneath a $25-\mathrm{cm}$ radius, circular steel plate (Raper and Erbach, 1990b). An experiment was carried out in the soil bins at the NSDL that used this plate to apply a $25-\mathrm{kN}$ load to the soil surface. Three replications of the experiment were performed and measurements of soil condition and surface deformation were recorded. The SSTs developed at the NSDL were also used to measure the stresses in the soil at two depths $(15$ and $25 \mathrm{~cm})$ and at two radial locations (at the center and at $20 \mathrm{~cm}$ radially) beneath the flat plate.

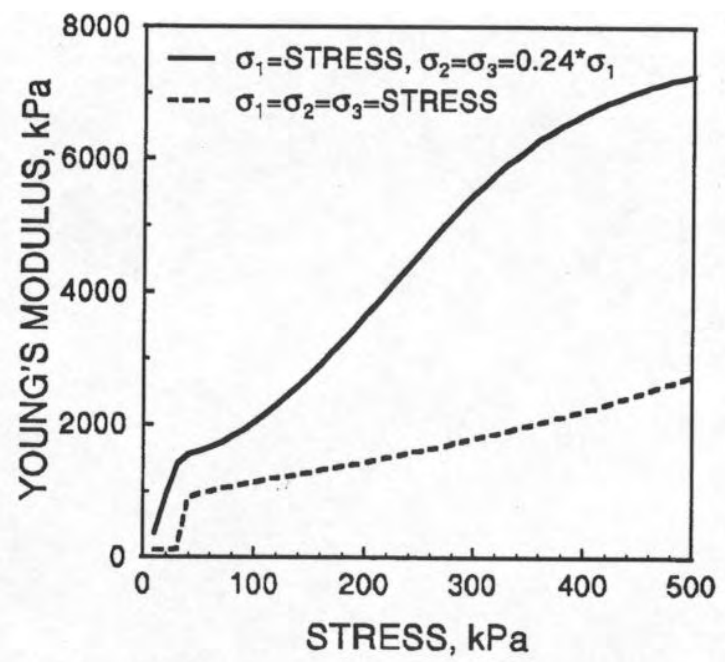

Figure 2-Young's modulus is predicted for a Norfolk sandy loam soil assuming either (a) the minor principal stresses, $\sigma_{2}$ and $\sigma_{3}$, are calculated from equation 7 , or (b) all the principal stresses are equal.

The average of the surface deformations $(19.6 \pm 0.7 \mathrm{~cm})$ recorded from the laboratory experiment were used to incrementally load the finite element model. Stress values from comparable depths in the finite element model were compared with results from the laboratory experiment. Stresses compared were vertical, octahedral normal (mean normal), major principal, and octahedral shearing.

\section{Results AND Discussion}

Generally, the stress levels predicted by the finite element soil compaction model exceeded the $95 \%$ confidence intervals of the SST-measured-values in seven of 16 cases. At the shallow SST depths, all predictions were within the confidence intervals, but near the hardpan, the predictions were not as accurate.

For the predicted vertical stress contours (fig. 3), both of the shallow points were within a $95 \%$ confidence interval (table 1). The deep center point was not predicted accurately because of the extremely tight confidence interval. The deep radial value was narrowly missed by the model. Measured values of the shallow radial SST were $227 \pm 145 \mathrm{kPa}$ with a predicted value of $239 \mathrm{kPa}$ while the

\section{VERTICAL STRESS, $\mathrm{kPa}$}

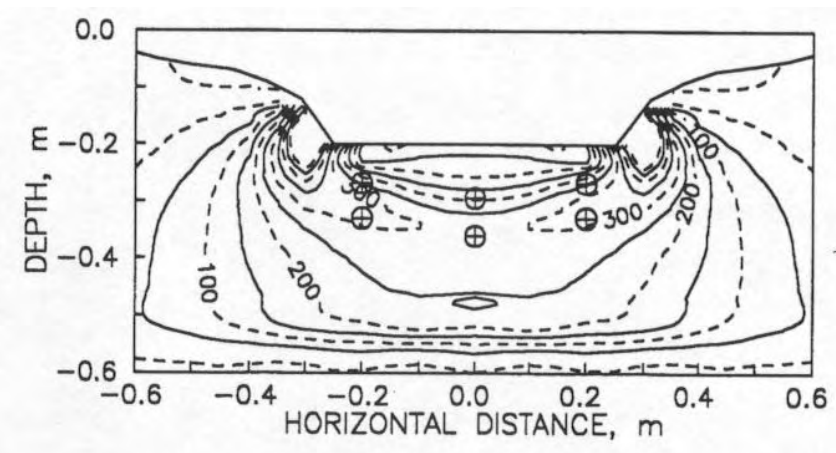

Figure 3-Iso-stress graph of vertical stress in the soil profile after a flat plate has applied a load to the soil surface. The circles indicate locations of the SSTs in the soil. 
Table 1. Stress values and $95 \%$ confidence intervals measured with the SSTs in the soil bin experiment along with their predicted values from the finite element model*

\begin{tabular}{|c|c|c|c|c|}
\hline $\begin{array}{l}\text { Location } \\
\text { of } \\
\text { SST }\end{array}$ & $\begin{array}{l}\text { Vertical } \\
\text { Stress } \\
(\mathrm{kPa})\end{array}$ & $\begin{array}{l}\text { Octahedral } \\
\text { Normal } \\
\text { Stress (kPa) }\end{array}$ & $\begin{array}{c}\text { Major } \\
\text { Principal } \\
\text { Stress (kPa) }\end{array}$ & $\begin{array}{l}\text { Octahedral } \\
\text { Shearing } \\
\text { Stress (kPa) }\end{array}$ \\
\hline \multirow{2}{*}{$\begin{array}{l}\text { Shallow } \\
\text { center } \\
\text { Predicted }\end{array}$} & $267 \pm 173$ & $106 \pm 66$ & $277 \pm 165$ & $123 \pm 69$ \\
\hline & 182 & 89 & 182 & 76 \\
\hline \multirow{2}{*}{$\begin{array}{c}\text { Deep } \\
\text { center } \\
\text { Predicted }\end{array}$} & $231 \pm 17$ & $89 \pm 24$ & $236 \pm 11$ & $106 \pm 10$ \\
\hline & 271 & 133 & 271 & 98 \\
\hline \multirow{2}{*}{$\begin{array}{l}\text { Shallow } \\
\text { radial } \\
\text { Predicted }\end{array}$} & $227 \pm 145$ & $83 \pm 51$ & $248 \pm 185$ & $122 \pm 90$ \\
\hline & 239 & 105 & 241 & 96 \\
\hline \multirow{2}{*}{$\begin{array}{c}\text { Deep } \\
\text { radial } \\
\text { Predicted }\end{array}$} & $163 \pm 97$ & $61 \pm 47$ & $173 \pm 76$ & $82 \pm 18$ \\
\hline & 307 & 149 & 312 & 115 \\
\hline
\end{tabular}

deep radial SST registered $163 \pm 97 \mathrm{kPa}$ with a predicted value of $307 \mathrm{kPa}$.

The measured octahedral normal stresses had about the same variation as the vertical normal stresses (table 1). Stresses at all four locations were close to the predicted values (fig. 4). Again, though, the predicted values tended to be greater than the measured values for the deep positions of the SSTs.

Because the vertical stress was generally much larger than the radial or tangential component of stress, its magnitude was generally very close to the major principal stress value (fig. 5). The finite element model's prediction of the major principal stress was very similar to its prediction of vertical stress.

The octahedral shearing stress was predicted closer than the other values because of it ability to be predicted accurately at the deep center depth (fig. 6). The only position that was not predicted accurately was the deep radial position that had measured values of $82 \pm 18 \mathrm{kPa}$ with a predicted value of $148 \mathrm{kPa}$.

The incorporation of the shearing stress component into the compaction model had a significant beneficial effect on the results emanating from the finite element model. Previous research by Raper and Erbach (1990b) which modeled a flat circular plate and used equation 1 as the constitutive relationship (and used octahedral normal stress

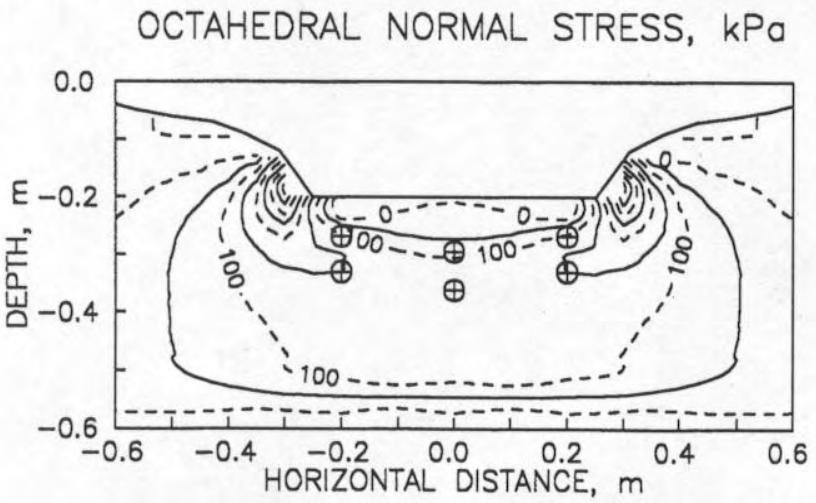

Figure 4-Iso-stress graph of octahedral normal stress in the soil profile after a flat plate has applied a load to the soil surface. The circles indicate locations of the SSTs in the soil.

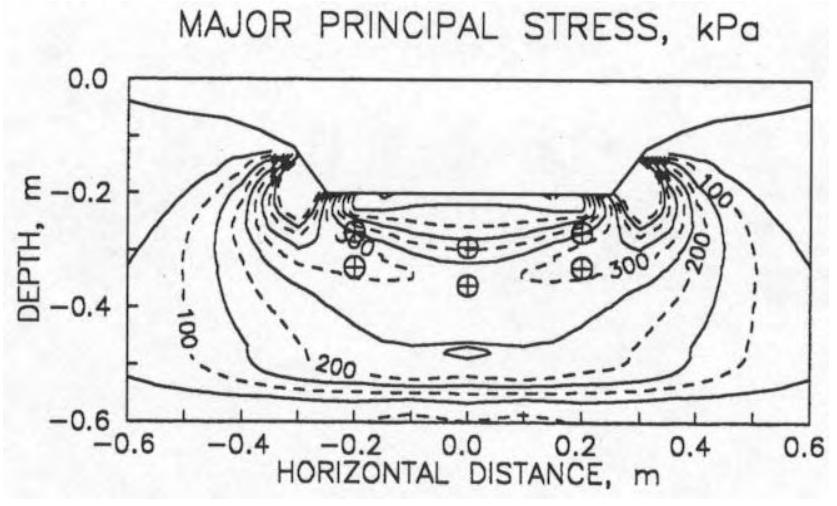

Figure 5-Iso-stress graph of major principal Stress in the soil profile after a flat plate has applied a load to the soil surface. The circles indicate locations of the SSTs in the soil.

in place of hydrostatic stress) predicted vertical stress and octahedral normal stress contours approximately $40 \%$ less than the current model at the deep SST location. The magnitudes of these values from previous research fell mostly within the $95 \%$ confidence interval, while the current model generally exceeds this interval for these parameter.

The inclusion of the octahedral shearing stress component into the compaction model caused the finite element model to predict significantly higher stress values at the deep SST location. The reason for the decreased prediction efficiency is not clear. It either comes directly from including the shearing stress component into the soil compaction model or indirectly from the methods that are required due to the presence of shearing stress. Research shows that Poisson's ratio fixes the stress state in a finite element model (Raper and Erbach, 1990a). Poisson's ratio is dependent on the relationship of shearing strain to stress state. The relationship used in this research as proposed by Grisso et al. (1987) was extrapolated beyond the range of Grisso's data to the point of plastic flow. Additional research is needed to determine this parameter more accurately.

\section{Conclusions}

- Proposed modifications to the engineering mechanics definitions of Poisson's ratio and

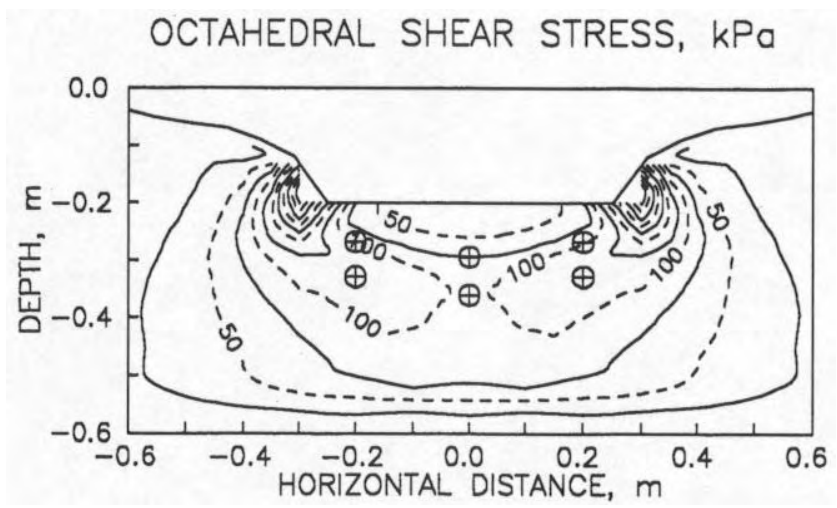

Figure 6-Iso-stress graph of octahedral shearing stress in the soil profile after a flat plate has applied a load to the soil surface. The circles indicate locations of the SSTS in the soil. 
Young's modulus resulted in predictions of reasonable values for agricultural soil.

- The soil compaction model developed by Bailey and Johnson (1989) that used both octahedral normal and shearing stresses coupled with a linear shearing strain relationship from Grisso et al. (1987) were successfully incorporated into an axisymmetric finite element model.

- Vertical stress, major principal stress, and octahedral normal and shearing stress as predicted from the finite element model were within the $95 \%$ confidence interval of the shallow SST values measured in the laboratory experiment. However, the finite element model predicted excessive values at the deeper SST location.

\section{REFERENCES}

Bailey, A. C.. C. E. Johnson and R. L. Schafer. 1984. Hydrostatic compaction of agricultural soils. Transactions of the ASAE 27(4):952-955.

Bailey, A. C. and C. E. Johnson. 1989. A soil compaction model for cylindrical stress states. Transactions of the ASAE 32(3):822-825.

Beer. F. P. and E. R. Johnston. Jr. 1981. Mechanics of Materials. 585 New York: McGraw-Hill.

Chancellor. W. J.. R. H. Schmidt and W. Soehne. 1962. Soil

Deformation and compaction during piston sinkage.

Transactions of the ASAE 5(2):235-239.
Duncan, J. M. and C. Y. Chang. 1970. Nonlinear analysis of stress and strain in soils. J. Soil Mechanics and Foundations Div., Proc. Am. Soc. Civil Eng. 96(.5): 1629-1653.

Grisso, R. D.. C. E. Johnson and A. C. Bailey. 1987. The influence of stress path on distortion during soil compaction. Transactions of the ASAE 30(5):1302-1307.

Larson, W. E., S. C. Gupta and R. A. Useche. 1980. Compression of agricultural soils from eight soil orders. Soil Sci. Soc. Am. J. 44(3):450-457.

Nichols, T. A., A. C. Bailey, C. E. Johnson and R. D. Grisso. 1987. A stress state transducer for soil. Transactions of the ASAE 30(5):1237-1241.

Perumoral. J. V. 1969. The finite element method for predicting stress distribution and soil deformation under a tractive device. Unpub. Ph.D. diss., Purdue Univ, West Lafayette, Ind.

Popov, E. P. 1976. Mechanics of Materials, 41. Englewood Cliffs, N.J.: Prentice-Hall Inc.

Raper, R. L. and D. C. Erbach. 1990a. Effect of variable linear elastic parameters on finite element prediction of soil compaction. Transactions of theASAE 33(3):731-736. $1990 \mathrm{~b}$. Prediction of soil stresses using the finite element method. Transactions of the ASAE 33(3):725-730.

Soehne. W. 1958. Fundamentals of pressure distribution and soil compaction under tractor tires. Agricultural Engineering May 276,281,290.

Vanden Berg, G. E., W. F. Buchele and L. E. Malvern. 1958. Application of continuum mechanics to soil compaction. Transactions of the ASAE 1(1):24-27. 